\title{
The Application of Multimedia Technology and Situational Teaching Method in English Classroom of Grade 6 in Primary Schools-Taking the Teaching Design of Unit 1, Volume 2 of Grade 6 in Oxford Shanghai Edition as an Example
}

\author{
Yueyue Lin \\ School of Foreign Languages, East China University of Science and Technology, Shanghai, China \\ Email: 1786077071@qq.com
}

How to cite this paper: Lin, Y.Y. (2022) The Application of Multimedia Technology and Situational Teaching Method in English Classroom of Grade 6 in Primary SchoolsTaking the Teaching Design of Unit 1, Volume 2 of Grade 6 in Oxford Shanghai Edition as an Example. Open Access Library Journal, 9: e8387.

https://doi.org/10.4236/oalib.1108387

Received: January 20, 2022

Accepted: February 18, 2022

Published: February 21, 2022

Copyright $\odot 2022$ by author(s) and Open Access Library Inc.

This work is licensed under the Creative Commons Attribution International License (CC BY 4.0).

http://creativecommons.org/licenses/by/4.0/

\begin{abstract}
With the continuous deepening of the national education reform, the traditional teaching model is no longer suitable for primary school English education, which means that English teachers are speeding up exploring a new teaching model. This article mainly analyses and discusses the application of multimedia technology and situational teaching method in English teaching of grade six in elementary school, hoping to be helpful to teaching practice.
\end{abstract}

\section{Subject Areas \\ Foreign Language Teaching}

\section{Keywords}

Situational Teaching, Multimedia, Primary English Teaching

\section{Introduction}

Shanghai is one of the most developed central cities in China in terms of economy, culture, technology and education. It is also one of the iconic cities of reform and opening-up. As early as the early 1990s, Shanghai began to offer English courses on a large scale from the third grade of elementary school. In 1998, it was the first to offer English classes in some elementary schools from the 
first grade [1]. Shanghai's current elementary education resources are more abundant than other cities. The faculty of public schools and the advanced level of teaching equipment are at the top level in China. Therefore, teachers should make full use of advanced multimedia technology and combine various teaching methods to create a relaxed and happy English learning atmosphere. The author believes that the use of multimedia technology can effectively promote situational teaching. This article selects Unit 1, Volume 2 of Grade 6 in Oxford Shanghai edition as teaching material. In the teaching design, the author mainly combines multimedia with specific teaching methods and creates situations before class to enhance students' interest, listening, and reading. The teaching part adopts the situational teaching method.

The "English Curriculum Standards" pointed out: "The goal of the basic education stage is to develop student's language skills, language knowledge, emotional attitudes, learning strategies and cultural awareness based on the development of students' comprehensive language skills" [2]. "It is necessary to provide students with independent learning. The opportunity to communicate with each other and space to express oneself fully" [3]. The "opportunity" and "space" refer to the language environment in which students learn. Elementary school English situational teaching means that teachers create as naturally as possible in class. Situational teaching provides good examples for language functions, allowing students to engage in English conversations in authentic contexts. The entire teaching process is centered on listening and speaking activities. Students can obtain more and more authentic opportunities for practice. To a greater extent, it stimulates students' motivation for language practice and is conducive to students' participation in language practice. The outstanding feature of situational teaching is that it should be carried out in a natural context and a good language environment. Students' interest in learning English can be maintained and developed, which dramatically extends students' language learning time range.

The situational teaching method has been used in teaching practice for a long time, and the educational thoughts of ancient Greece and Rome have already had valuable guiding thoughts. The great philosopher Socrates's "art of midwifery" uses teacher-student conversations to create specific problem situations to enable students to think independently to solve problems. This seemingly simple teaching method is the development of activity theory based on dialogue teaching. Become the bud of situational teaching method. The origins of this approach began with the work of British applied linguists in the 1920s and 1930s. Two of the leaders in this movement were Harold Palmer (1877-1949) and A. S. Hornby (1898-1978), two of the most prominent British twentieth-century language teaching figures. Both were familiar with the work of such prominent linguists of the time as the Danish grammarian Otto Jespersen and the phonetician Daniel Jones, as well as with the Direct Method. They attempted to develop a more scientific foundation for an oral approach to teaching English than was evidenced in the Direct Method [4]. The result was a systematic study of the 
principles and procedures that could be applied to the selection and organization of the content of a language course [5] [6]. More and more domestic scholars have been concerned about applying situational teaching methods in primary school English teaching in recent years. Under the influence of constructivism, behaviorism, psychology, and especially the theory of contextual cognition, "contextualization" emerged in Chinese English teaching reforms. New concepts such as "situational listening" "interactive teaching methods" have emerged. "Situational reading," "cognitive English teaching method," "three-dimensional integrated teaching method," "cooperative learning method" have caused a surge of "contextualization" in English teaching in our country.

Multimedia and tradition way of teaching will be complementary and lead the new trend of teaching [7]. Multimedia teaching aboard is derived from audio-visual instruction, or named audio-visual education programme domestically. This later developed into computer aided instruction and computer teaching. With the development of technology, there has emerged multimedia technology with computer at its core and multimedia-aided teaching. In traditional way of teaching, knowledge in textbooks and coaching materials is developed in a linear way with a logic order. In the course of teaching, students are passive and dependent on teachers and lack the flexibility of self-study. In contrast, multimedia teaching is organized in a way that fits human perception. It can make up for the weaknesses in traditional teaching [8].

The multimedia classroom teaching model is based on two major theories: cognitive learning theory and constructivist learning theory. The cognitive view of learning believes that learning should be an internalization process, processing and fusing new knowledge with the original cognitive structure to form a new cognitive structure. The traditional classroom teaching model of scrambling teaching ignores the initiative of students. Students do not actively acquire new knowledge but passively accept knowledge in the process of learning. The classroom teaching model based on network multimedia constantly brings freshness to students by enriching network resources and stimulating students' desire to challenge. Students can automatically and consciously process and internalize the new knowledge they will learn. According to Bruner, the learning process is produced by learners to satisfy their own cognitive needs. This is the process of stimulating internal motivation. Therefore, English learning should also start with the students' own needs, start with reality. The teacher needs to choose topics that students are interested in for discussion, give full play to the advantages of network resources, and return the English classroom to students with audio, video, and other multimedia methods.

The constructivists believe that learning must occur in a specific context. Students can independently construct meaning through group cooperation. In traditional English teaching, teachers divide the language into single words and sentences to explain meaning word by word. This method is inefficient and violates the laws of students' cognitive development. And due to the limitations of 
classroom space and resources, teachers cannot effectively create situations. The integration of network multimedia makes up for this shortcoming. Teachers can use many online videos and audios with rich pictures, use computer technology to create real language situations for students, and bring students into the situation through electronic devices, integrating online and offline classrooms. Carry out group activities, guide students to acquire knowledge in-group cooperation, and establish a classroom teaching model with students as the main body. As an essential branch of cognitive learning theory, constructivism involves a wide range of ideas. It comes from Piaget's epistemology, L. S. Vygotsky's (1896-1934) language acquisition theory, postmodernist views on science, feminist epistemologists, and theories of philosophy of science, American psychologist Kelly's individual construction theory. Gao Wen argues that a vital conclusion derived from constructivist beliefs is that each of us imagines the external world differently, based on our unique set of experiences about the world and our beliefs about those experiences [9].

With Shanghai version of the theme of "Great Cities in Asia" of the Oxford English, for example, teachers can be found that the English class can break the traditional teaching mode, create the teaching situation and the application of multimedia technology to enhance the course more interesting, improve students' comprehensive language using ability, keep students' interest in learning English, further to improve their learning efficiency.

\section{Textbook Analysis}

The Shanghai edition of Oxford English textbooks organically integrates language structure and function, constructs language through sentence structure and rich vocabulary, and achieves the purpose of helping students to have preliminary communication. The content of this textbook is more suitable for students' lives, full of the breath of the times, and easy to stimulate students' enthusiasm for learning. The Shanghai version of the Oxford English textbook takes themes and topics as the module units. The language materials of each unit are developed around a theme in the context of related topics, and the teaching content of each grade is interrelated. This textbook content is relatively practical for students [10].

This article selects the first unit of the second book of the sixth grade-Great Cities in Asia. The teaching content focuses on the cultural experience. This teaching design aims to let students understand the main countries and cities in Asia and involve some countries' historical sites and distinct cultures. This course involves special sentences guided by "How" and "Which" with new sentence patterns, which are used to ask about the way, time, and distance. Starting from Chinese and foreign cultures, the author takes Asian cities and Asian culture as the topic to set up the learning content and expand the learning process, so that students can understand the cities and cultures at home and abroad. Therefore, the author pays attention to cultivating students' listening, speaking, 
reading, writing, practicing and using six abilities in teaching.

\section{Student Analysis}

After nearly six years of English learning, students in grade six have initially developed good learning habits. The vast majority of students have mastered and accumulated a certain number of vocabulary and some important and common grammar and tense, and preliminarily have certain listening, speaking, reading and writing skills. Grade 6 students have a strong thirst for knowledge and desire to perform. Differences in family learning environment, parents' attention to students' learning, and high-density and large-capacity teaching materials make the learning gap between different students bigger and bigger. Before learning this class, students have learned the vocabulary related to the city and location, and can use them to describe the city, location and other related content, which has laid a certain language foundation for the classroom learning. Therefore, students have mastered a lot of knowledge, teachers should pay more attention to the organic combination of knowledge and interest in teaching, make full use of various teaching means to improve students' interest in learning, improve students' learning efficiency.

\section{Teaching Design}

Teachers need to use various teaching methods to integrate multimedia teaching equipment into teaching reasonably, improving teaching efficiency while mobilizing students' classroom atmosphere. Multimedia technology has the advantage of combining pictures, texts, audio, and images. When applied to teaching activities, it can present abstract and complex knowledge intuitively and dynamically to understand it better. Multimedia teaching can fully mobilize students to participate in teaching with multiple senses. Students can imitate voice and intonation more authentically, which can prevent students from speaking Chinese English or even English with local accents.

The teacher is just an organizer, guide, collaborator, and instructor. Students are the main body of learning activities. Only when teachers actively guide students to participate in learning activities can they truly display their enthusiasm and creativity. The theme of this unit is "Great cities in Asia." The author divides this unit into three lessons and provides practical guidance.

Three module units of this unit will be divided into three parts, aiming at listening and speaking, reading and writing respectively. Each teaching fragment will develop with situational and multimedia teaching methods.

\subsection{Teaching Fragment 1: Listening and Speaking}

\subsubsection{Teaching Plan}

At First, the teacher can introduce the topic of "holiday travel" to mobilize the children's enthusiasm. Next, the teacher should display some maps through multimedia. Teachers should offer a school map or a city map that students are 
familiar with, and then the world map in the textbook. The teacher can create a situation that a man is looking up the map so that everyone can claim a landmark and tell the location. In the "listening and say" part of page 2, the teacher can also use multimedia to display different means of transportation. Photos and videos can be displayed together. The teacher can first ask students the correct way of travel by asking questions, leading them to learn the sentence patterns of "How far" and "How long," After the case, through the creation of scenarios, do some drills and practice the dialogue of $\mathrm{P} 4$.

\subsubsection{Teaching Method}

In the first teaching fragment, the primary teaching method is the oral and situational method. New language points are introduced and practiced situationally. The target language is the language of the classroom [4]. Creating a good English classroom learning atmosphere is necessary to mobilize children's enthusiasm and carry out effective teaching. Teachers should speak English as much as possible in the classroom so that children can gradually understand. Suppose someone is going to visit a big city in Asia. The other person in the conversation can ask about the location of the city and what transportation tool one can choose.

\subsection{Teaching Fragment 2: Reading}

\subsubsection{Teaching Plan}

The students have basically mastered the locations of several major countries and cities on the map. The following teachers can use multimedia to present pictures or short videos to introduce students to the three capital cities of Asia: Beijing, Tokyo, and Bangkok. Of course, teachers can also show pictures and ask students to guess proper terms such as cities and scenic spots. There are not many new vocabularies that aim to train students to obtain information through different forms such as listening and reading and introducing the cities they like and understand. Before class, students can be arranged to preview, find pictures and information of specific cities.

\subsubsection{Teaching Method}

The "English Curriculum Standards" proposes that the grade six of primary school graduates should reach the second level. In the aspect of reading, it is required to "be able to read simple stories or short essays with the help of pictures and develop the habit of reading according to the meaning of the group". In this part, the teacher can create scenarios with the help of multimedia technology, let the students assume that they are going to travel and let them talk about their travel plans as much as possible.

\subsection{Teaching Fragment 3: Writing}

\subsubsection{Teaching Plan}

Teachers can use quiz cards to ask questions to students to understand their mastery. After the previous study, students have mastered the relevant information of the above major cities. The teacher can ask the students to work in 
groups, allowing students to use the sentence patterns learned in this lesson to have conversations and express the countries and scenic spots they want to visit and how to get there. Next is pair work. Teachers can use multimedia to show some hand-drawn road maps and then ask each two students to draw their own travel poster. At last, all students in the class will vote to select the best poster award, best design award, and best text award for encouragement.

\subsubsection{Teaching Method}

In this part, the teacher can use the "task-based" situational teaching method. The task-based learning and teaching approach of English courses at the primary education stage emphasizes teaching from using language. It allows students to learn to complete a real task and require them to complete the tasks, enabling them to learn for application and use them after learning. It can directly cultivate students' ability to use language and show children that English is an exciting and practical communication tool [11]. "English Curriculum Standards" clearly points out that the characteristics of the task-based teaching mode are: learning English in the process of listening, talking, singing, drawing, playing, performing and doing, and teaching in a cheerful form that conforms to the psychological characteristics of children. The utilization of multimedia to display pictures and quiz cards also plays a crucial role in teaching.

The class ends with a competition, which is aligned with the characteristics of primary school students. Since they are competitive and aggressive, the use of competition in teaching can effectively improve the teacher's ability to control the class and help students enhance their sense of collective honour and develop a spirit of cooperation.

\subsection{Homework}

As an extension of classroom teaching of homework, after-school workbooks can help students consolidate the knowledge learned in class. For this given workbook, I have selected some exercises from it as homework. The after-class workbook and textbook content are highly matched, which helps students consolidate the knowledge they have learned. However, there are a large number of exercises, which will bring a burden to students. Therefore, I selected some more specific and interesting topics as homework.

\section{Reflection and Conclusion}

Firstly, the situational teaching method has certain drawbacks. Teachers should not set too many situations. Some students want to complete the tasks given by the teacher and lack thinking about the content of knowledge, which deviates from the basic ideas of teaching, and students cannot learn too many things. Therefore, teachers should continue to strengthen the emphasis and research on the situational teaching method. Based on the characteristics and cognitive level of primary school students, teachers are supposed to rationally use the situational teaching method to make up for the shortcomings of the traditional reading 
teaching model, to improve the efficiency and level of primary school English teaching and promote students' comprehension.

Secondly, in the teaching process, teachers should design different dialogue scenarios for students at different levels so that students at different levels have something to say. In classroom teaching, teachers should give them some drill tasks that are less difficult to express in oral expression as much as possible to cultivate their self-confidence and sense of accomplishment. Before performing a performance or situational dialogue, the teacher can demonstrate to everyone like a director, giving them enough time to prepare what they are saying and prepare the conversation plan. If possible, teachers can inform them one day in advance of the activities to be carried out the next day. They can first send some information to them and solicit the opinions of the students in the class.

Thirdly, teachers should reflect on their teaching after class. Teachers cannot put all activities before class, which misinterprets the goal of situational experience teaching. After-class reflection is also a higher requirement for teachers and students. Traditional teaching only pays attention to the teaching effect of the classroom and ignores the summary after class. After-class reflection is the summary of the class by teachers and students. The teacher's classroom design should be well reflected in the pre-class preparation and after-class reflection [12].

\section{Conflicts of Interest}

The author declares no conflicts of interest.

\section{References}

[1] Shu, D.F., Li, Z.W. and Zhang, Y.G. (2003) Investigation and Reflection on English Teaching in Primary Schools in Shanghai. Foreign Language World, No. 3, 54-62.

[2] Chinese Ministry of Education (2011) English Curriculum Standards for Compulsory Education (2011 Version). Beijing Normal University Press, Beijing. http://www.moe.gov.cn/srcsite/A26/s8001/201112/t20111228 167340.html

[3] Liu, S.Z. (2003) English Curriculum Concept and Implementation. Guangxi Education Press, Nanning, 98.

[4] Richard, J.C. and Rodgers, T.S. (2014) Approaches and Methods in Language Teaching. Cambridge University Press, Cambridge.

[5] Palmer, H.E. (1917) The Scientific Study and Teaching of Languages. Oxford University Press, London.

[6] Palmer, H.E. (1921) Principles of Language Study. World Book Co., New York.

[7] Wang, Z.X. (2005) Design and Implementation of Multimedia Remote Teaching Assistant System. Master's Thesis, Dalian University of Technology, Dalian, 3-8.

[8] Zhang, X. (2014) Research on the Gray Hierarchy Evaluation Model Based on Multimedia System and English Teaching Evaluation. International Journal of Multi-Media \& Ubiquitous Engineering, 9, 181-192. https://doi.org/10.14257/ijmue.2014.9.8.16

[9] Gao, W. (2002) The Revolution of Human Learning in the 21st Century. East China Normal University Press, Shanghai. 
[10] Yang, X.X. (2018) Create a Situation to Improve the Efficiency of Primary School English Review Class-Take a Review Session in the Shanghai Edition of Oxford English for Example. Education Observation, 7, 91-93.

[11] Guo, Y.Z. and Guo, R.Z. (2004) Diversified Multimedia Primary School English and “Task-Based" Situational Teaching. Journal of Shaanxi Normal University (Philosophy and Social Sciences Edition), No. S2, 399-400.

[12] Lv, T. (2012) The Application of Situational Experiential Teaching Mode in Primary School English Teaching. Modern Primary and Secondary Education, No. 9, 36-39. 


\section{Appendix A. (Abstract and Keywords in Chinese)}

多媒体技术与情景教学法在小学六年级英语课堂中的应用一以上海牛 津版六年级第二册第一单元的教学设计为例

摘要: 随着国家教育改革的不断深化, 传统的教学模式早已经不再适用于小 学英语教育, 意味着英语教师加快探索出全新教学模式的进度。本文主要对 多媒体技术和情境教学法在小学六年级英语教学中的应用进行分析和探讨, 希望能够为教学实践带来帮助。

关键词: 情景教学, 多媒体, 小学英语教学

\section{Appendix B. (Teaching Plan)}

\section{Unit Analysis}

\subsection{Special Questions}

Ask about the way-How are you going to get to XXX?

Ask about the length of time it will take to do something-How long does it take?

Ask about the distance-How far is it from XX to XX?

Ask about the orientation-Where is XXX?

Ask about the capital-Which city is the capital of XXX?

\subsection{Orientation}

East, south, west, north, north-west, south-west, south-east, north-west.

\subsection{Preposition}

By

\section{Teaching Target}

1) Be able to use How-sentence to ask about the distance and the length of time something will take. Learn to use "It's about XX kilometers" and "It takes about XX minutes" to answer questions.

2) Be able to use the prepositions that go with transportation correctly, especially the "by."

3) To master "V+ doing," such as "love easting" and "enjoy swimming."

4) To know some culture of some great cities in Asia.

\section{Unit Points}

\subsection{Keywords}

1) The names of countries and cities: Asia, Beijing, China, Tokyo, Japan, Bangkok, Thailand.

2) Vocabularies related to tourism and exhibition: exhibition, travel, building, tourist, famous, kilometer, palace, huge. 
3) Orientation: east, south, west, north, north-west, south-west, south-east, north-west.

4) Some else: enjoy, nowadays, quiz.

\subsection{Grammar Points}

1) Sing orientation to show the position

It is east of Beijing.

2) Asking "How" questions to find out the means/ the length of a time/ distance.

-How far is it from Shanghai to Beijing?

-How can we travel to Beijing?

-How long does it take to travel from Shanghai to Beijing?

3) Using prepositional phrase to indicate means by train/ship/train.

4) Asking "Wh-“ questions to find out about a place/a specific object or specific information.

-Which city is the capital of XX?

-What do people in Bangkok love eating?

-What can tourists find in Bangkok?

-Where do tourists always visit in Beijing?

-What do tourists enjoy doing in Beijing?

\section{Teaching Designs}

\subsection{Listening and Speaking}

Step 1: Since this class is the first lesson of the school, most students have travel experience during the summer vacation. Teachers can introduce the topic of "holiday tourism" into the classroom. Teachers can use multimedia to display a map of Asia and take the students and students to read the map together, including icons. Allow students to grasp the expression of the eight basic directions.

Step 2: In the listening and say part of Page 2, teachers can also use multimedia to display different means of transportation. Teachers can first ask students the correct way of travel by asking questions, leading them to learn the sentence patterns of "How far" and "How long," After the case, through the creation of scenarios, do some drills and practice the dialogue of $\mathrm{P} 4$.

\subsection{Reading}

Step 1: The previous students have basically mastered the locations of several major countries and cities on the map. The following teachers can use multimedia to present pictures or short videos to introduce students to the three capital cities of Asia: Beijing, Tokyo, and Bangkok. Of course, teachers can also show pictures and ask students to guess proper terms such as cities and scenic spots.

Step 2: Vocabulary. There are not many new vocabularies. The class aims to train students to obtain information through different forms such as listening 
and reading and introducing the cities they like and understand. Before class, students can be arranged to preview, find pictures and information about specific cities.

\subsection{Writing}

Step 1: Teachers can use quiz cards to ask questions to students to understand their mastery.

Step 2: After the previous study, students have mastered the relevant information of the above major cities. Now teachers can cooperate in groups and create situations, allowing students to use the sentence patterns learned in this lesson to have conversations and express the countries and scenic spots they want to visit. And how to get there. You can draw your own travel routes by hand, and all students in the class will vote to select the best poster award, best design award, and best text award for encouragement.

\section{Homework}

Read and write on Page 2, Reading and tick on Page 6, Read and write on Page 7. 